Supplementary Information for

\title{
Remarkable Enhancement in the Nonlinear Optical Responses of Porphyrins Realized by Combination with Polyoxometalates via Covalent Bonding: A Case Study
}

Sadaf ul Hassan, ${ }^{\mathrm{a}}$ Yunshan Zhou, ${ }^{\mathrm{ab}}$ Lijuan Zhang, ${ }^{\text {a }}$ Zonghai Shi, ${ }^{\mathrm{a}}$ Di Yang, ${ }^{\mathrm{a}}$ Hafiz Muhammad Asif ${ }^{\mathrm{a}}$ and Ningning $\mathrm{Qu}^{\mathrm{a}}$

${ }^{a}$ State Key Laboratory of Chemical Resource Engineering, Institute of Science, Beijing University of Chemical Technology, Beijing 100029, P. R. China.

${ }^{b}$ Laboratory of Optical Physics, Institute of Physics, Chinese Academy of Sciences, Beijing 100190, P. R. China

Table S1. Selected ${ }^{1} \mathrm{H}$ NMR data of $\mathrm{NH}_{2} \mathrm{TPPH}_{2}, \mathrm{NH}_{2} \mathrm{TPPZn}, \mathrm{F} @ \mathrm{TPPH} \mathrm{H}_{2}, \mathrm{~F} @ \mathrm{TPPZn}$, compounds 1 and $\mathbf{2}$ in ppm.

\begin{tabular}{cccccc}
\hline No. & Compounds & $-\mathrm{NH}_{2}$ & $-\mathrm{NH}-$ & $-\mathrm{NH}-\mathrm{C}=\mathrm{O}$ & $\mathrm{O}=\mathrm{C}-\mathrm{NH}-\mathrm{C}$ \\
\hline 1 & $\mathrm{NH}_{2} \mathrm{TPPH}_{2}$ & 4.01 & -2.71 & - & - \\
2 & $\mathrm{NH}_{2}$ TPPZn & 4.03 & - & - & - \\
3 & F@TPPZn & - & - & 8.14 & - \\
4 & F@TPPH & - & -1.98 & 8.48 & - \\
5 & Compound 1 & - & - & 7.21 & 6.37 \\
6 & Compound 2 & - & -2.59 & 6.86 & 5.98 \\
\hline
\end{tabular}

Table S2. Peaks observed at different $\mathrm{m} / \mathrm{z}$ values and their corresponding formulas with intensities by using ESI-MS spectrum for compounds $\mathbf{1}$ and $\mathbf{2}$

\begin{tabular}{ccccc}
\hline Entry Charge & ${ }^{\mathrm{a})}$ Calcd. & Observed & Rel. Int. & ${ }^{\mathrm{b}}$ Composition \\
& $\mathrm{m} / \mathrm{z}$ & $\mathrm{m} / \mathrm{z}$ & $(\%)$ &
\end{tabular}


Compound 1

\begin{tabular}{|c|c|c|c|c|c|}
\hline 1 & $2-$ & 3039 & 3039 & 99.98 & $\left\{\left(\mathrm{Bu}_{4} \mathrm{~N}\right)_{4}[\text { Dawson-F@TPPZn }]\right\}^{2-}$ \\
\hline 2 & $3-$ & 1959 & 1958 & 23.12 & $\left\{\left(\mathrm{Bu}_{4} \mathrm{~N}\right)_{3}[\text { Dawson-F@TPPZn }]\right\}^{3-}$ \\
\hline 3 & $3-$ & 1890 & 1890 & 16.34 & $\left\{\left(\mathrm{Bu}_{4} \mathrm{~N}\right)_{2} \mathrm{~K}[\text { Dawson-F@TPPZn }]\right\}^{3-}$ \\
\hline 4 & $3-$ & 1822 & 1822 & 17.01 & $\left\{\left(\mathrm{Bu}_{4} \mathrm{~N}\right) \mathrm{K}_{2}[\text { Dawson-F@TPPZn }]\right\}^{3-}$ \\
\hline 5 & $3-$ & 1755 & 1755 & 11.92 & $\left\{\mathrm{~K}_{3}[\text { Dawson-F@TPPZn }]\right\}^{3-}$ \\
\hline 6 & $4-$ & 1417 & 1418 & 46.31 & $\left\{\left(\mathrm{Bu}_{4} \mathrm{~N}\right)_{2}[\text { Dawson-F@TPPZn }]\right\}^{4-}$ \\
\hline 7 & $4-$ & 1367 & 1367 & 28.82 & $\left\{\left(\mathrm{Bu}_{4} \mathrm{~N}\right) \mathrm{K}[\text { Dawson-F@TPPZn }]\right\}^{4-}$ \\
\hline 8 & $4-$ & 1316 & 1316 & 29.14 & $\left\{\mathrm{~K}_{2}[\text { Dawson-F@TPPZn }]\right\}^{4-}$ \\
\hline 9 & $5-$ & 1093 & 1093 & 47.71 & $\left\{\left(\mathrm{Bu}_{4} \mathrm{~N}\right)[\text { Dawson-F@TPPZn }]\right\}^{5-}$ \\
\hline
\end{tabular}

Compound 2

10

2- $\quad 3051 \quad 3051$

99.93

$\left\{\left(\mathrm{Bu}_{4} \mathrm{~N}\right)_{4}\left[\text { Dawson-F@TPPH}{ }_{2}\right]\right\}^{2-}$

11

3-

1967

1967

15.33

$\left\{\left(\mathrm{Bu}_{4} \mathrm{~N}\right)_{3}\left[\text { Dawson-F@TPPH} \mathrm{H}_{2}\right]\right\}^{3-}$

12

3-

1897

1898

14.17

$\left\{\left(\mathrm{Bu}_{4} \mathrm{~N}\right)_{2} \mathrm{~K}\left[\text { Dawson-F@TPPH }{ }_{2}\right\}^{3-}\right.$

13

3-

1831

1832

16.08

11.02

$1763 \quad 1763$

1424

1424

33.77

4-

4-

1358

1358

29.02

4-

1322

1322

29.78

$\left\{\left(\mathrm{Bu}_{4} \mathrm{~N}\right) \mathrm{K}_{2}\left[\text { Dawson-F@TPPH }{ }_{2}\right]\right\}^{3-}$

18

5-

1098

1098

50.64

$$
\left\{\mathrm{K}_{3}[\text { Dawson-F@TPPH }]\right\}^{3-}
$$

$\left\{\left(\mathrm{Bu}_{4} \mathrm{~N}\right)_{2}\left[\text { Dawson-F@TPPH }{ }_{2}\right]\right\}^{4-}$

$\left\{\left(\mathrm{Bu}_{4} \mathrm{~N}\right) \mathrm{K}\left[\text { Dawson-F@ } \mathrm{TPPH}{ }_{2}\right]\right\}^{4-}$

$$
\left\{\mathrm{K}_{2}[\text { Dawson-F@TPPH }]\right\}^{4-}
$$

$\left\{\left(\mathrm{Bu}_{4} \mathrm{~N}\right)\left[\text { Dawson-F@ } \mathrm{TPPH}_{2}\right]\right\}^{5-}$ 


$$
\begin{gathered}
{ }^{\mathrm{a}}[\mathrm{M}+\mathrm{K}]^{+} ;{ }^{\mathrm{b}} \mathrm{Bu}_{4} \mathrm{~N}=\mathrm{C}_{16} \mathrm{H}_{36} \mathrm{~N} ;[\text { Dawson-F@TPPZn }]=\left[\left\{\mathrm{C}_{52} \mathrm{H}_{32} \mathrm{~N}_{5} \mathrm{O}_{2} \mathrm{Zn}\right\} \mathrm{HNC}\left(\mathrm{CH}_{2} \mathrm{O}\right)_{3} \mathrm{P}_{2} \mathrm{~V}_{3} \mathrm{~W}_{15} \mathrm{O}_{59}\right] \\
\left.\left.\cdot 2 \mathrm{C}_{4} \mathrm{H}_{9} \mathrm{NO}\right]^{6-} ;[\text { Dawson-F@TPPH }]=\left[\left\{\mathrm{C}_{52} \mathrm{H}_{34} \mathrm{~N}_{5} \mathrm{O}_{2}\right\} \mathrm{HNC}\left(\mathrm{CH}_{2} \mathrm{O}\right)_{3} \mathrm{P}_{2} \mathrm{~V}_{3} \mathrm{~W}_{15} \mathrm{O}_{59}\right] \cdot 3 \mathrm{C}_{4} \mathrm{H}_{9} \mathrm{NO}\right]^{6-}
\end{gathered}
$$

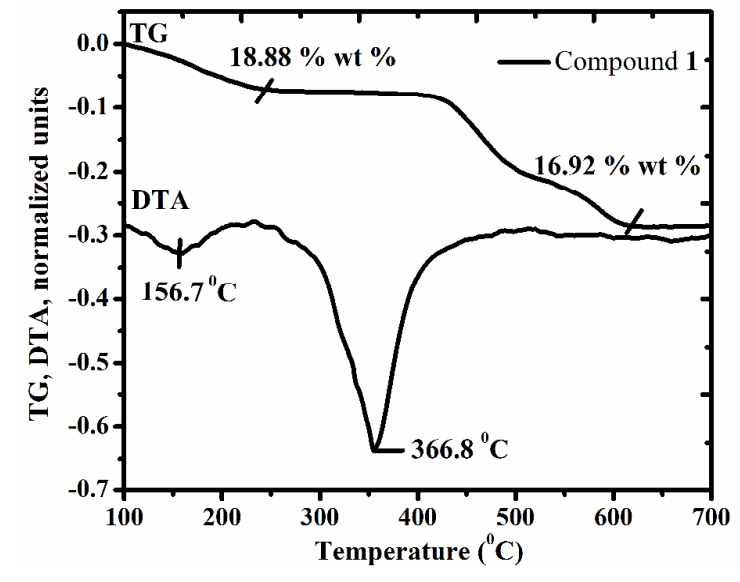

a

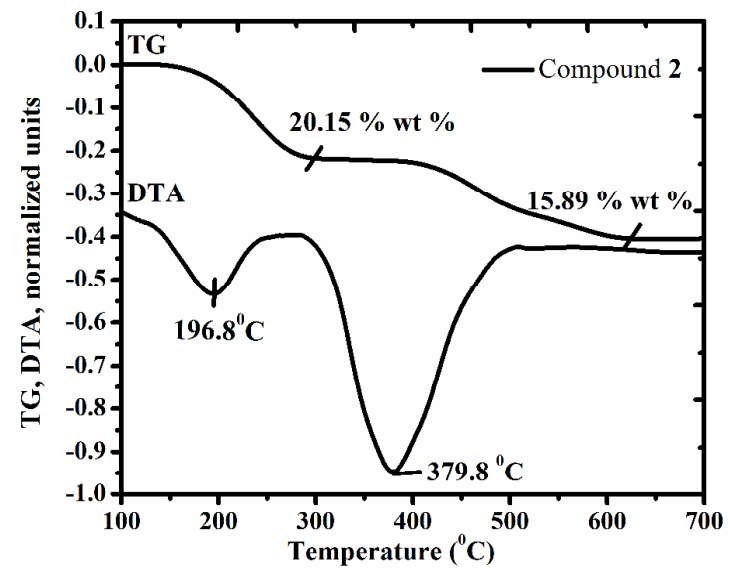

b

Figure S1. TG-DTA plot of compounds 1 (a) and 2 (b).

\section{Third-order nonlinear optical measurements}

Figure S2 shows the experimental setup of Z-scan technique, which is a well-known and efficient technique for the determination of the nonlinear optical parameters of materials, providing simultaneously the thirdorder nonlinear susceptibilities, the magnitude of nonlinear absorption as well as sign of the nonlinear refraction. An EKSPLANL-303 Q-switched Nd:YAG laser with a wavelength of $\lambda=532 \mathrm{~nm}$, a pulse duration of $\tau=6 \mathrm{~ns}$, and a repetition rate of $10 \mathrm{~Hz}$ with intensity of light at the focus $E_{0}$ of $20 \mu \mathrm{J}$ was employed as the light source. A portion of the input beam is divided by a beam splitter and measured by a photo detector to determine the incident energy on the entrance face of the sample. The other beam propagated in the $z$-direction and passed through the sample. The sample is translated along the $z$-direction and with nonlinear refractive index causes an additional, depending on $z$, focusing (at positive $n_{2}$ ) or defocusing (at negative $n_{2}$ ) of the light beam. It changes the transmitted intensity of the beam passing through a finite aperture placed in the far-field when moving the sample along $z$ (closed aperture Z-scan). For an open aperture Z-scan, the aperture was removed to collect the entire laser beam transmitted through 


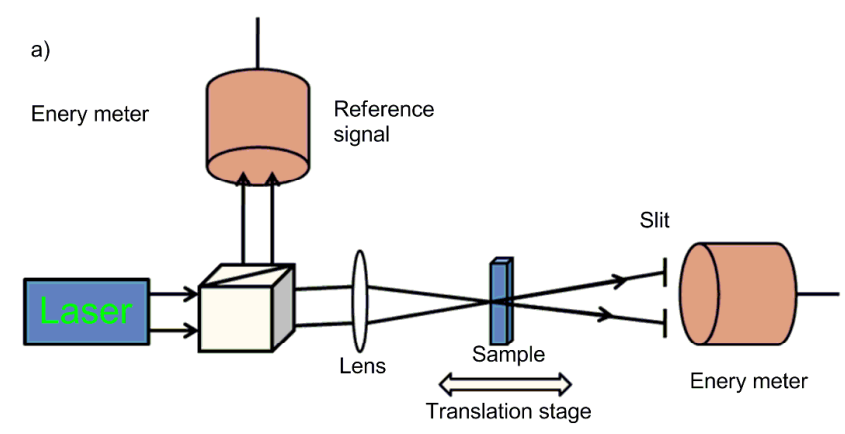

b)

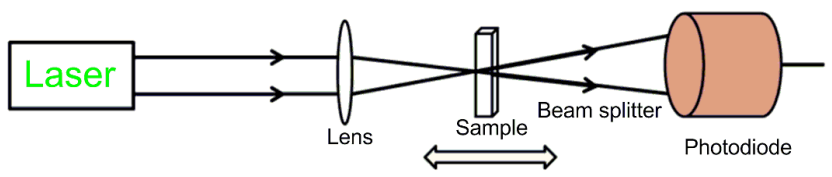

Figure S2. Experimental setup for (a) closed aperture Z-scan and (b) open aperture Z-scan.

the sample. The intensity of the transmitted beam through the sample was measured with closed- and openaperture scheme using the photo detector fed to the digital power meter. The linear transmittance of the farfield aperture S (defined as the ratio of the pulse energy passing through the aperture to the total pulse energy) was measured to be 0.25 . The laser beam (i.e., GAUSSIAN light beam), after being focused by a $20 \mathrm{~cm}$ focal length lens into the sample placed in a $L=1 \mathrm{~mm}$ path-length quartz cell, was passed though the a large-area beam splitter. Before the measurements, the system was calibrated using $\mathrm{CS}_{2}$ in quartz cell as reference.

The following formulas are used to calculate the third-order nonlinear refractive index $n_{2}$ (esu), the nonlinear absorption coefficient $\beta$ (esu) and the third-order optical nonlinear susceptibility $\chi^{(3)}$ (esu). ${ }^{1}$

$$
\begin{array}{ll}
\Delta T_{P-V}=0.406(1-S)^{0.25}\left|\Delta \varphi_{0}\right|, & \\
\Delta \varphi_{0}=k L_{\text {eff }} \gamma I_{0}, & \text { (Equation S1) } \\
L_{e f f}=\left(1-e^{\alpha_{0} L}\right) / \alpha_{0}, & \text { (Equation S3) } \\
n_{2}(e s u)=\frac{c n_{0}}{40 \pi} \gamma\left(\mathrm{m}^{2} / \mathrm{W}\right), & \text { (Equation S4) }
\end{array}
$$

where, $\Delta T_{P-V}$ is the normalized peak-valley difference, $\Delta_{\varphi 0}$ is the phase shift of the beam at the focus, $K=$ $2 \pi / \lambda$ is the wave vector, $I_{o}$ (unit: $\mathrm{W} / \mathrm{m}^{2}$ ) is the intensity of the light at focus, Leff is the effective length of the sample defined in terms of the linear-absorption coefficient $\alpha_{0}$ and the true optical path length through 
the sample, $n_{0}$ is the linear refractive index, and $\gamma$ is optical Kerr constant. The conversion can be realized between $n_{2}$ (esu) and $\gamma\left(\mathrm{m}^{2} / \mathrm{W}\right)$ by equations (S4).

When the sample is measured under open aperture, the normalized transmittance $T(z, s=1)$ can be expressed as

$T(z, s=1)=\sum_{m=0}^{\infty} \frac{\left[q_{0}(z)\right]^{m}}{(m+1)^{3 / 2}}$,

(Equation S5)

Where, $q_{0}(z)=\beta I_{0} L_{\text {eff }} /\left(1+z^{2} / z_{0}^{2}\right), \beta$ is nonlinear absorption coefficient.

From equation (S5) we can get $\beta$. From equation (S6-S8), we can get the third-order optical nonlinear susceptibility $\operatorname{Im} \chi^{(3)}, \operatorname{Re} \chi^{(3)}$ and $\chi^{(3)}$.

$$
\begin{array}{cl}
\operatorname{Im} \chi^{(3)}(\mathrm{esu})=\left(\mathrm{n}_{0}{ }^{2} \mathrm{c}^{2} / 240 \pi^{2} \omega\right) \beta(\mathrm{m} / \mathrm{W})=100 \lambda \mathrm{n}_{0} \beta(\mathrm{esu}) / 6 \pi^{2} & \text { (Equation S6) } \\
\operatorname{Re} \chi^{(3)}(\mathrm{esu})=\mathrm{n}_{0}^{2} \mathrm{c} \gamma\left(\mathrm{m}^{2} / \mathrm{w}\right) / 120 \pi^{2}=\mathrm{n}_{0} \mathrm{n}_{2}(\mathrm{esu}) / 3 \pi & \text { (Equation S7) } \\
\chi^{(3)}=\sqrt{\left(\frac{c n_{0}}{160 \pi^{2}} \gamma\right)^{2}+\left(\frac{c \beta n_{0}^{3} \lambda}{64 \pi^{3}}\right)^{2}}, \quad \text { (Equation S8) }
\end{array}
$$

The molecular second hyperpolarizability $\gamma$ of the samples was calculated by following equation. ${ }^{15}$

$$
\gamma=\frac{\chi^{(3)}}{N_{c} L}
$$

Where $n_{0}$ is the linear refractive index of sample, $N_{\mathrm{c}}$ is the molecular number density per cubic centimeter, and $L$ is the local-field correction factor, which may be approximated by $\left[\left(n_{0}{ }^{2}+2\right) / 3\right]^{4}$. $^{2}$
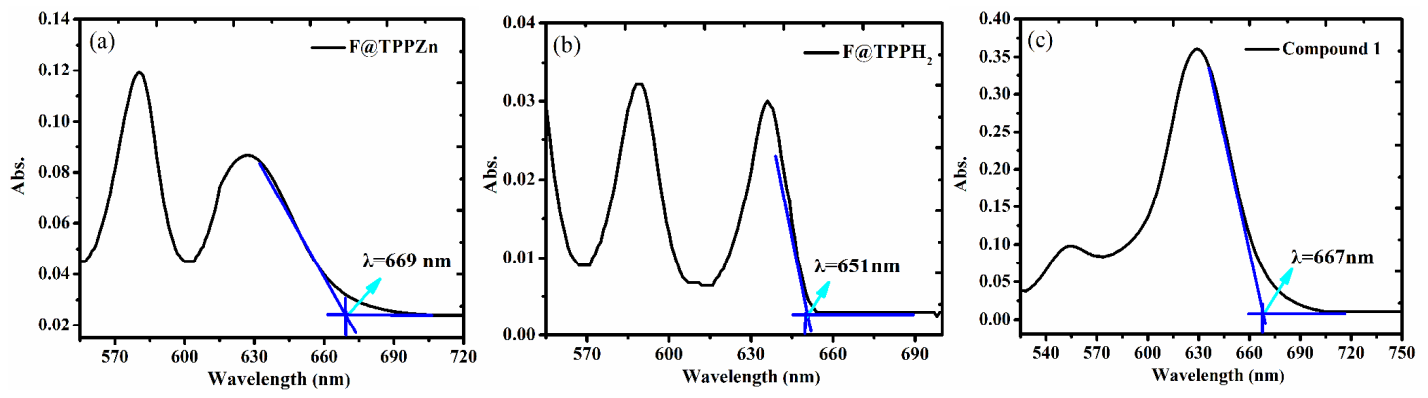

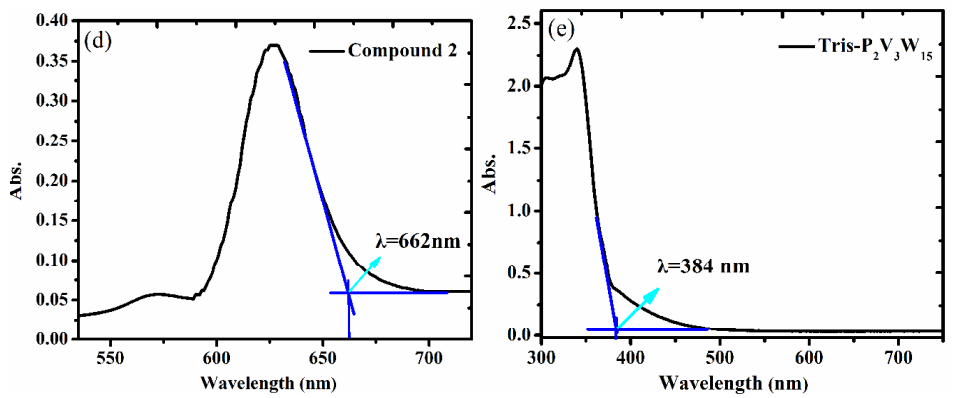

Figure S3. UV-vis. spectra of (a) F@TPPZn, (b) F@TPPH 2 , (c) compound 1, (d) compounds 2 and Tris$\mathrm{P}_{2} \mathrm{~V}_{3} \mathrm{~W}_{15}$ (e) in THF (all the compounds have the concentrations of $2.4 \times 10^{-5} \mathrm{M}$ ) highlighting the absorption edges corresponding to the HOMO-LUMO gap $E_{\mathrm{g}}$ values of the compounds, respectively.

\section{Reference}

(1) Sheik-Bahae, M.; Said, A.; Wei, T.; Hagan, D.; Stryland E. V., IEEE J. Quant. Electron. 1990, 26 , $760-769$.

(2) Wang, S. F.; Huang, W. T.; Zhang, Q.; Gong, T. Q. H.; Okuma, Y.; Horikiri M.; Miura, Y. F. Appl.

Phys. Lett. 1999, 75, 1845-1847. 